\title{
Evaluation of a rapid method for the determination of plasma fibrinogen
}

H. B. C. BURMESTER, K. AUlTON, AND G. I. HORSFiEld

From the Department of Pathology, St Luke's Hospital, Bradford, Yorkshire

SYNOPSIS In this study the method of Ellis and Stransky (1961) to determine plasma fibrinogen is evaluated, and modifications are described which have been introduced to improve the sensitivity and reduce the time taken for the test.

Hypofibrinogenaemia has become increasingly recognized as a major factor in the bleeding disorders of pregnancy during the past decade. Most of the methods for the measurement of fibrinogen are lengthy and require considerable technical skill and experience to obtain reliable results. Schneider (1951) introduced the thrombin titre method which has the advantage of simplicity, and a modification of this is now generally used in emergencies.

Ellis and Stransky (1961), using a thrombin reagent to polymerize fibrinogen, measured the turbidity produced spectrophotometrically and expressed the results as fibrinogen concentration. Bottema and Vervoort (1964) later extended the technique to demonstrate fibrinolysis.

Experience with these two methods has shown that accurate fibrinogen determinations are difficult at low levels due to low sensitivity and that the time taken for the test may lead to a delay in treatment.

\section{Materials and Methods}

Venous blood is anticoagulated with one tenth Received for publication 20 March 1969.

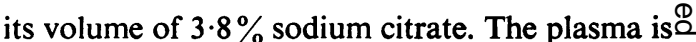
separated by centrifugation at $3,000 \mathrm{rpm}$ for $\overrightarrow{\hat{O}}$ three minutes.

\section{REAGENTS}

1 Barbitone-saline buffer, $0 \cdot 1 \mathrm{M}, p \mathrm{H} 7 \cdot 2: \frac{0}{3}$ $2.93 \mathrm{~g}$ sodium chloride and $5.71 \mathrm{~g}$ sodium. di-ethyl barbiturate are dissolved in about $900 \mathrm{ml}$ deionized water. The solution is titrated with 1.0 N hydrochloric acid to $p \mathrm{H} \mathrm{7.2} \mathrm{using} \mathrm{a} p \mathrm{H}$ 응 meter. About $22.5 \mathrm{ml}$ is required. Make the volume to 1 litre with water.

2 Calcium chloride, $3.38 \mathrm{M}$

3 Sodium chloride, $0.9 \%$

4 Thrombin (Parke-Davis) is reconstituted in saline to a concentration of $1,000 \mathrm{NIH}$ units $\mathrm{N}$ per $\mathrm{ml}$.

5 Calcium-thrombin reagent, for which $0.1 \mathrm{mlo}$ reconstituted thrombin is diluted with $1.9 \mathrm{ml}$ $0.9 \%$ sodium chloride and $2.0 \mathrm{ml} 3.38 \mathrm{M}$ calcium ${ }^{+}$ chloride, is added. After mixing this reagent is stored at $4^{\circ} \mathrm{C}$ when not in use and has a useable life $\frac{\mathrm{O}}{\mathrm{P}}$ of at least 24 hours.

TECHNIQUE

The recording spectrophotometer (Unicam? SP800A) is programmed to read changes inō 
absorbance against time at a fixed wavelength of $300 \mathrm{~nm}$.

Plasma, $0.5 \mathrm{ml}$, is diluted with $5.5 \mathrm{ml}$ barbitonesaline buffer in a test tube and $3.0 \mathrm{ml}$ of the mixture carefully transferred to a $1 \mathrm{~cm}$ silica cuvette for the test. The remainder of the mixture is decanted into a similar cuvette as a blank. Both cuvettes are placed in the spectrophotometer and the instrument is adjusted to zero absorbance.

Of the calcium-thrombin reagent, $0.015 \mathrm{ml}$ is added to the contents of the test cuvette and mixed rapidly and carefully to minimize the production of air bubbles. The cuvette is replaced in the spectrophotometer and the programme started. The trace is drawn for at least 10 minutes.

\section{CALCULATION}

The absorbance at $300 \mathrm{~nm}$ at the end of the 10 minutes is noted and substituted in the following

formula $\left(E_{300}^{10^{\prime}}\right)$ :-

Plasma fibrinogen $=$

$\left(\begin{array}{c}\text { E } 10^{\prime} \\ 300\end{array} \times 325\right)+16 \times \frac{10}{9} \mathrm{mg} / 100 \mathrm{ml}$.

The factor 10 is to correct for anticoagulant dilution.

$$
\overline{9}
$$

\section{dilution.}

\section{Experimental and Results}

\section{WAVELENGTH}

Initial experiments with the Ellis-Stransky technique confirmed that at $470 \mathrm{~nm}$, the wavelength used by these workers, sensitivity was inadequate for the measurement of low levels of fibrinogen.

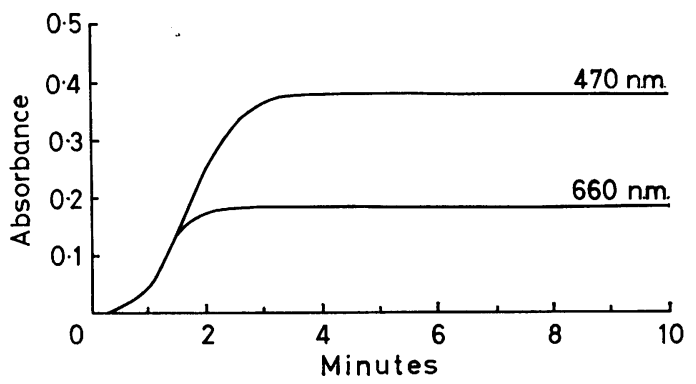

Fig 1 Comparison of sensitivity by the methods of Ellis and Stransky at $470 \mathrm{~nm}$ and Bottema and Vervoort at $660 \mathrm{~nm}$ on a sample of plasma with a fibrinogen level of $315 \mathrm{mg} / 100 \mathrm{ml}$ determined chemically.
A further experiment carried out at $660 \mathrm{~nm}, a \S$ used by Bottema and Vervoort (1964), showed leş sensitivity (Fig. 1).

A fibrinogen determination was carried ou according to our technique and after 20 minutes a complete spectral scan was recorded over the range $215-700 \mathrm{~nm}$ (Fig. 2). There was no peak of absorbance but a general increase in absorbancs with decrease in wavelength. Below $280 \mathrm{~nm}$ the trace became very 'noisy', and therefore 300 nr was selected as the working wavelength, since्巳 this provides maximum sensitivity.

\section{TIME}

Ellis and Stransky (1961) used the absorbane readings obtained after 20 minutes to calculate fibrinogen levels. A series of experiments wås carried out to establish the optimum time at which to take readings. It was confirmed that a truto plateau was not reached at 60 minutes but the rate of increase in absorbance at this time was very slow. The average of the readings at 180 minutes was $95 \%$ of the readings obtained 60 minutes and at 20 minutes the average reading was $98 \%$ of the 60 -minute values. We consider that the 10-minute readings provide sufficien accuracy consistent with the need for a rapies result and all subsequent readings are made it this time.

\section{LINEARITY}

A number of serial dilutions of plasma in salire were examined by the technique and the resule show that the readings are linear below an absor ance value of 1.00 unit (Fig. 3).

\section{REPRODUCIBILITY}

A series of 20 plasma samples at varying fibrine gen levels was analysed singly on two separate

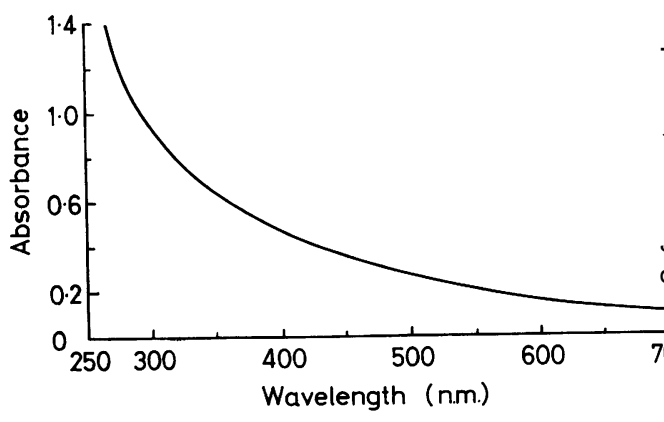

Fig 2 Absorption spectrum of the reaction mixture after 20 minutes. 


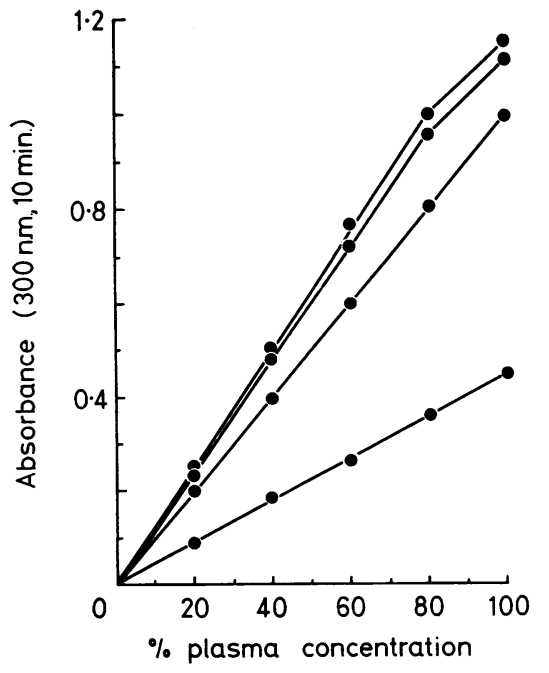

Fig 3 Linearity of the modified technique. Each curve is derived from a different specimen of plasma.

occasions. The results are shown in Table $I$. The standard deviation (SD) of the duplicates is \pm 0.018 absorbance units. The $95 \%$ confidence limits of \pm 2 SD is \pm 0.036 absorbance units (equivalent to $\pm 12 \mathrm{mg}$ fibrinogen). The chart of the Unicam SP800A can be read to 0.005 absorbance units.

\section{CALIBRATION}

The reference method was a modification of the

\begin{tabular}{|c|c|c|c|}
\hline \multirow{2}{*}{ Sample No. } & \multicolumn{3}{|c|}{ Absorbance (300 $\mathrm{nm}$ at 10 minutes) } \\
\hline & First Analysis & Second Analysis & Difference $(d)$ \\
\hline $\begin{array}{r}1 \\
2 \\
3 \\
4 \\
5 \\
6 \\
7 \\
8 \\
9 \\
10 \\
11 \\
12 \\
13 \\
14 \\
15 \\
16 \\
17 \\
18 \\
19 \\
20\end{array}$ & $\begin{array}{l}0.925 \\
0.515 \\
0 \cdot 260 \\
0 \cdot 280 \\
0 \cdot 130 \\
0.900 \\
0.095 \\
0.390 \\
0 \cdot 275 \\
0 \cdot 370 \\
0 \cdot 845 \\
0.180 \\
0.090 \\
0.275 \\
0.980 \\
0.185 \\
0.380 \\
0.085 \\
0.370 \\
0.185\end{array}$ & $\begin{array}{l}0.875 \\
0.515 \\
0.250 \\
0.275 \\
0.130 \\
0.935 \\
0.090 \\
0 \cdot 390 \\
0 \cdot 280 \\
0 \cdot 375 \\
0 \cdot 800 \\
0 \cdot 185 \\
0.090 \\
0 \cdot 290 \\
0.995 \\
0 \cdot 185 \\
0.370 \\
0.085 \\
0.385 \\
0.185\end{array}$ & $\begin{array}{l}0.050 \\
0.000 \\
0.010 \\
0.005 \\
0.000 \\
0.035 \\
0.005 \\
0.000 \\
0.005 \\
0.005 \\
0.045 \\
0.005 \\
0.000 \\
0.015 \\
0.015 \\
0.000 \\
0.010 \\
0.000 \\
0.015 \\
0.000\end{array}$ \\
\hline 20 & Stan & $\begin{array}{l}\text { Sum of differences } \\
\text { Mean of differences } \\
\text { eviation of difference } \pm\end{array}$ & $\begin{array}{l}0.220 \\
0.011 \\
0.018\end{array}$ \\
\hline
\end{tabular}

Table I Reproducibility of the technique at different fibrinogen levels

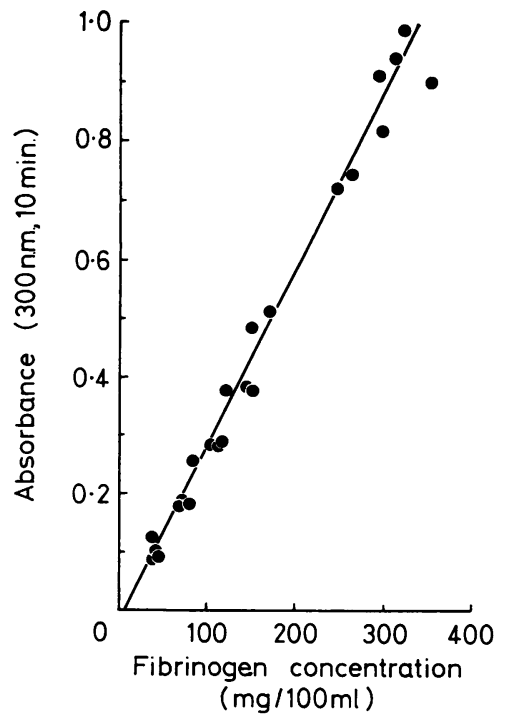

Fig 4 Correlation between the results of fibrinogen assay on 23 plasma samples by the proposed modification (ordinate) and the method of Ratnoff and Menzie (abscissa). Each point represents the means of duplicate analyses by each method.

procedure of Ratnoff and Menzie (1951). In this modification protein was precipitated, collected and washed as in the original technique, and then dissolved in $4 \mathrm{ml} 0.2 \mathrm{~N}$ sodium hydroxide by heating in a boiling water bath for 15 minutes. After cooling, $0.2 \mathrm{ml} 4 \%$ copper sulphate was added and the tubes were shaken vigorously for about a minute. The colour was developed by incubating the tubes at $37^{\circ} \mathrm{C}$ for 20 minutes and the optical density at $560 \mathrm{~nm}$ was observed after centrifuging at $2,500 \mathrm{rpm}$ for two minutes. A standard was prepared with each batch of analyses by diluting $0.1 \mathrm{ml}$ standard protein solution with $3.9 \mathrm{ml} 0.2 \mathrm{~N}$ sodium hydroxide, adding $4 \%$ copper sulphate, and developing the colour as in the tests. As a blank, $4 \mathrm{ml} 0 \cdot 2 \mathrm{~N}$ sodium hydroxide was treated with $4 \%$ copper sulphate and the colour developed.

Twenty-three plasma samples were analysed o in duplicate by this procedure and the same $N$ samples were analysed, again in duplicate, by our method.

The results are shown in Table II and illustrated in Figure 4.

Statistical analysis of these results shows a high degree of correlation between the two methods, $(r=0.9899)$. The regression data for the line of best fit as derived from the least squares formula is:-

$$
\mathrm{b}=324.68 \text { and } \mathrm{c}=16.06
$$

where $\mathrm{b}=$ slope of $x$ on $y$ and $\mathrm{c}=$ intercept. 


\begin{tabular}{llr}
\hline Sample No. & $\begin{array}{l}\text { Absorbance }(300 \mathrm{~nm} \text { at } \\
\text { lO min) by Modified } \\
\text { Ellis and Stransky } \\
\text { Method }\end{array}$ & $\begin{array}{l}\text { Fibrinogen }(\mathrm{mg} / 100 \mathrm{ml}) \\
\text { by Ratnoff and Menzie } \\
\text { Method }\end{array}$ \\
\hline 1 & $0 \cdot 745$ & 257 \\
2 & $0 \cdot 255$ & 86 \\
3 & $0 \cdot 375$ & 123 \\
4 & $0 \cdot 918$ & 290 \\
5 & $0 \cdot 390$ & 147 \\
5 & $0 \cdot 130$ & 42 \\
7 & $0 \cdot 900$ & 352 \\
8 & $0 \cdot 515$ & 172 \\
9 & $0 \cdot 715$ & 244 \\
10 & $0 \cdot 098$ & 47 \\
11 & $0 \cdot 278$ & 109 \\
12 & $0 \cdot 183$ & 85 \\
13 & $0 \cdot 378$ & 149 \\
14 & $0 \cdot 940$ & 310 \\
15 & $0 \cdot 085$ & 41 \\
16 & $0 \cdot 373$ & 154 \\
17 & $0 \cdot 185$ & 73 \\
18 & $0 \cdot 090$ & 48 \\
19 & $0 \cdot 988$ & 119 \\
20 & $0 \cdot 283$ & 113 \\
21 & $0 \cdot 278$ & 296 \\
22 & $0 \cdot 823$ & 73 \\
23 & $0 \cdot 185$ & \\
\hline
\end{tabular}

Table II Results of fibrinogen assay by the proposed modification and by the method of Ratnoff and Menzie $^{1}$

${ }^{1}$ Each value is the mean of duplicates.

Therefore, from the formula for a straight line, $y=\mathrm{b} x+\mathrm{c}$, plasma fibrinogen $=$

$\left(324.68 \times \mathrm{E}_{300}^{10^{\prime}}\right)+16.06$.

In practice the formula is simplified to

$\left(325 \times \mathrm{E}_{300}^{10^{\prime}}\right)+16$.

\section{Discussion}

From the results of these experiments we conclude that the original method as described by Ellis and Stransky (1961) can be modified so that both sensitivity and the time required to complete an analysis are improved. The fact that readings made after only 10 minutes give a value which is $95 \%$ of the value reached at 60 minutes does not appear to be a major disadvantage since it has been demonstrated that there is a very close correlation obtained with the reference procedure. Consequently no attempt has been made to correct for this difference. The experiments also show that there is linearity below an absorbance value of 1.00 unit, which is equivalent to a plasma fibrinogen level of $380 \mathrm{mg} / 100 \mathrm{ml}$. Although the lowest level of fibrinogen which can be determined is $18 \mathrm{mg} / 100 \mathrm{ml}$, differences of $2 \mathrm{mg}$ above this level can be detected. The value for $2 \mathrm{SD}$ of $\pm 12 \mathrm{mg}$ is well within the requirements of the technique and in clinical practice sufficiently accurate $\stackrel{C}{\overparen{C}}$ direct treatment.

With regard to the use of the method of Ratnaif and Menzie (1951) as a calibration procedure, th was selected because it measures 'thrombIn clottable protein' by the Biuret reaction as $\mathrm{d} \overrightarrow{\vec{F}}-$ tinct from direct spectrophotometry and because the method has been authenticated and is usegd extensively in clinical investigations. The man advantage of all the methods which use thromb茄 to separate fibrinogen from other plasma proteifiss is that they provide a measure of 'functionap' fibrinogen unlike the methods depending upe् chemical precipitation which may be affected to a varying degree by the split products of fibringlysis (Sharp, Howie, Biggs, and Methuen, 195\%).

The use of a recording spectrophotometer $8 \mathrm{r}$ our technique is not essential, but a reliabie ultraviolet spectrophotometer is necessary $\overrightarrow{\mathrm{d} O}$ produce the sensitivity although the calibration data would need to be verified for each instrume before routine use. One advantage of using $\rightarrow$ a recording instrument is that it can detect fibringlysis, since the curve shows a demonstrable fill after reaching a maximum absorbance value on some cases where plasmin is present in high concentrations. A similar fall can be obtained in vitro by adding streptokinase to the reaction mixture as described previously by Bottema aod Vervoort (1964) and this can be neutralizesd by the addition of one of the fibrinolytic inhibito

We have used this modification of the methodiof Ellis and Stransky in obstetrical practice in tope routine assessment of patients with antepartum haemorrhage, intrauterine death, and with bleegling after delivery. The main practical advantage is that an accurate and reliable result can rapidly obtained by a relatively simple proceduxe and therefore an initial assessment of the con tion and adequate monitoring of the response to therapy is readily available.

We should like to thank Dr R. J. Ord-Smith, Direcør of Computer Laboratories, Bradford University, for his assistance in statistical analysis; we should atso like to thank the nursing staff of the Maternity Hospital for their assistance in collecting specimens.

References

Bottema, J. K., and Vervoort, H. J. P. (1964). A rapid screeñing method for demonstrating fibrinolysis during surgefal operations. Clin. chim. Acta, 9, 179-182.

Ellis, B. C., and Stransky, A. (1961). A quick and accurate meth $7 \mathrm{~d}$ for the determination of fibrinogen in plasma. J. Lab. $\Phi_{i n}$. Med., 58, 477-488.

Ratnoff, O. D., and Menzie, C. (1951). A new method for determination of fibrinogen in small samples of plas $\$$ a. J. Lab. clin. Med., 37, 316-320.

Schneider, C. L. (1952). Rapid estimation of plasma fibrin\&en concentration and its use as a guide to therapy of intavascular defibrination. Amer. J. Obstet. Gynec., 64, 141-g7.

Sharp, A. A., Howie, B., Biggs, R., and Methuen, D. T. (19.9).

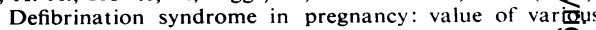
diagnost ic tests. Lancet, 2, 1309-1312. 